\title{
Mitigating Voltage Decay of Li-Rich Cathode Material via Increasing Ni-Content for Lithium-Ion Batteries
}

Ji-Lei Shi, ${ }^{\dagger, *}$ Jie-Nan Zhang, ${ }^{\#}$ Min He, ${ }^{\#}$ Xu-Dong Zhang, ${ }^{\dagger, *}$ Ya-Xia Yin,$^{\dagger}$ Hong Li ${ }^{\text {\# }}$

Yu-Guo Guo, ${ }^{* \dagger \dagger} \operatorname{Lin} G u,{ }^{*}$ and Li-Jun Wan ${ }^{* \dagger \dagger}, \dot{\dagger}$

${ }^{\dagger}$ Beijing National Laboratory for Molecular Sciences, CAS Key Laboratory of

Molecular Nanostructure and Nanotechnology, Institute of Chemistry, Chinese Academy of Sciences (CAS), Beijing 100190, (P. R. China).

\# Beijing National Laboratory for Condensed Matter Physics, Institute of Physics, Chinese Academy of Sciences (CAS), Beijing 100190, (P. R. China).

$\$$ University of Chinese Academy of Sciences, Beijing 100049, (P. R. China).

To whom correspondence should be addressed. E-mail: ygguo@iccas.ac.cn;

1.gu@iphy.ac.cn; wanlijun@iccas.ac.cn 


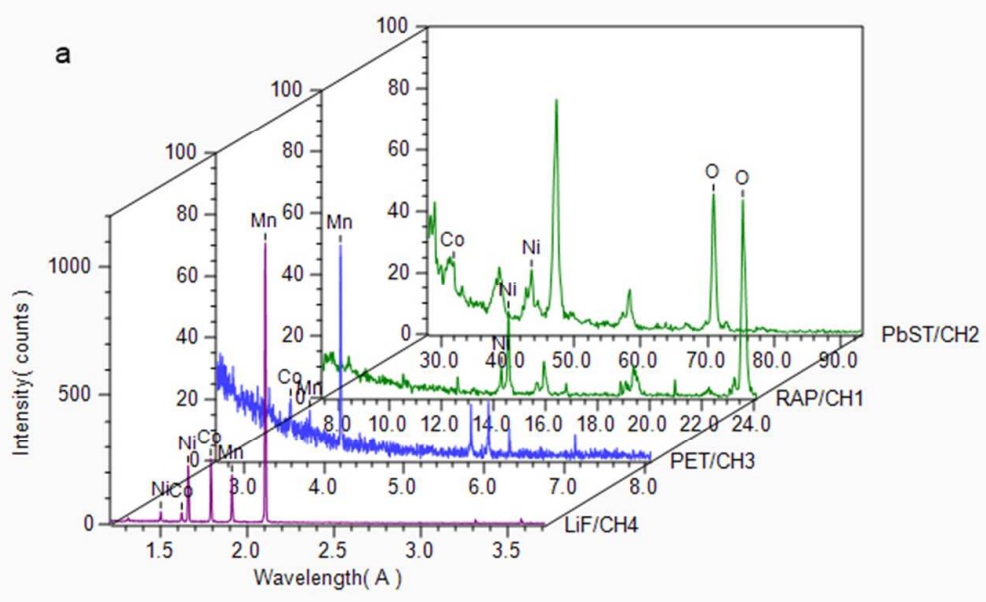

\begin{tabular}{|c|c|c|c|c|c|c|c|}
\hline No. & Element & Line & Crystal & Peak WL(A) & K-ratio & Mass $\%$ & At $\%$ \\
\hline 1 & 0 & $\mathrm{Ka}$ & $\mathrm{RAP} / \mathrm{CH} 1$ & 23.5990 & 0.37470 & 37.47 & 67.77 \\
\hline 2 & $\mathrm{Mn}$ & $\mathrm{Ka}$ & $\mathrm{LiF} / \mathrm{CH} 4$ & 2.1002 & 0.42157 & 42.16 & 22.21 \\
\hline 3 & Co & $\mathrm{Ka}$ & $\mathrm{LiF} / \mathrm{CH} 4$ & 1.7865 & 0.10315 & 10.32 & 5.06 \\
\hline 4 & $\mathrm{Ni}$ & $\mathrm{Ka}$ & $\mathrm{LiF} / \mathrm{CH} 4$ & 1.6551 & 0.10057 & 10.06 & 4.96 \\
\hline
\end{tabular}

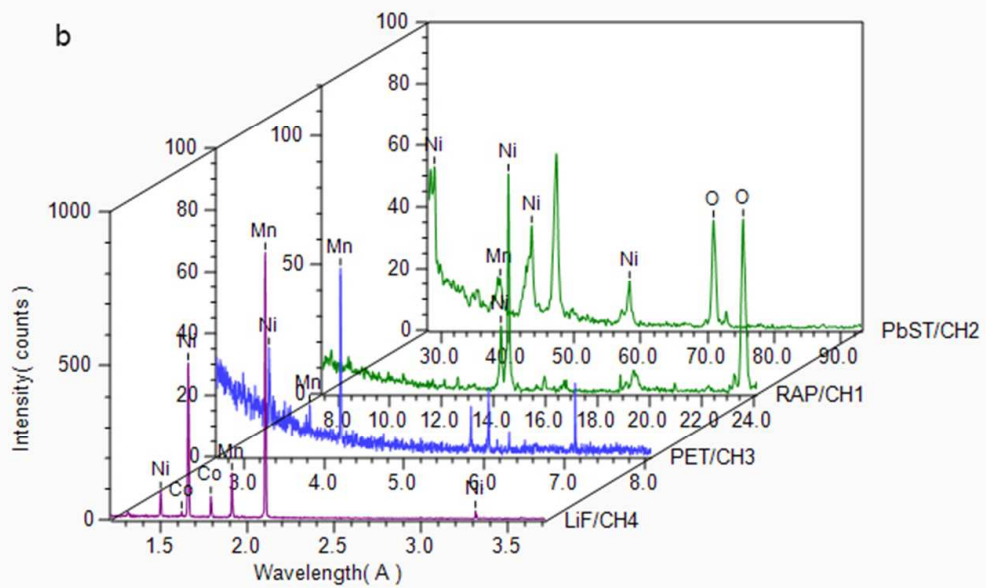

\begin{tabular}{|c|c|c|c|c|c|c|c|}
\hline No. & Element & Line & Crystal & Peak WL(A) & K-ratio & Mass $\%$ & At $\%$ \\
\hline 1 & 0 & $\mathrm{Ka}$ & $\mathrm{RAP} / \mathrm{CH} 1$ & 23.6106 & 0.38738 & 38.74 & 69.08 \\
\hline 2 & $\mathrm{Mn}$ & $\mathrm{Ka}$ & $\mathrm{LiF} / \mathrm{CH} 4$ & 2.1002 & 0.34410 & 34.41 & 17.87 \\
\hline 3 & Co & $\mathrm{Ka}$ & $\mathrm{LiF} / \mathrm{CH} 4$ & 1.7865 & 0.02989 & 2.99 & 1.45 \\
\hline 4 & $\mathrm{Ni}$ & $\mathrm{Ka}$ & $\mathrm{LiF} / \mathrm{CH} 4$ & 1.6557 & 0.23863 & 23.86 & 11.60 \\
\hline
\end{tabular}

Figure S1 (a) Pristine material of LL-111 the transition metal ratio of $\mathrm{Mn}: \mathrm{Co}: \mathrm{Ni}$ is 0.689:0.157:0.157 close to stoichiometric of pre-designed 0.666:0.166:0.166. (b) Pristine material of LL-811 the transition metal ratio of $\mathrm{Mn}: \mathrm{Co}: \mathrm{Ni}$ is 0.578:0.047:0.375 close to stoichiometric of pre-designed 0.55:0.05:0.40. The atomic percentages of each transition metal element are based on multiple EMPA analysis results. 


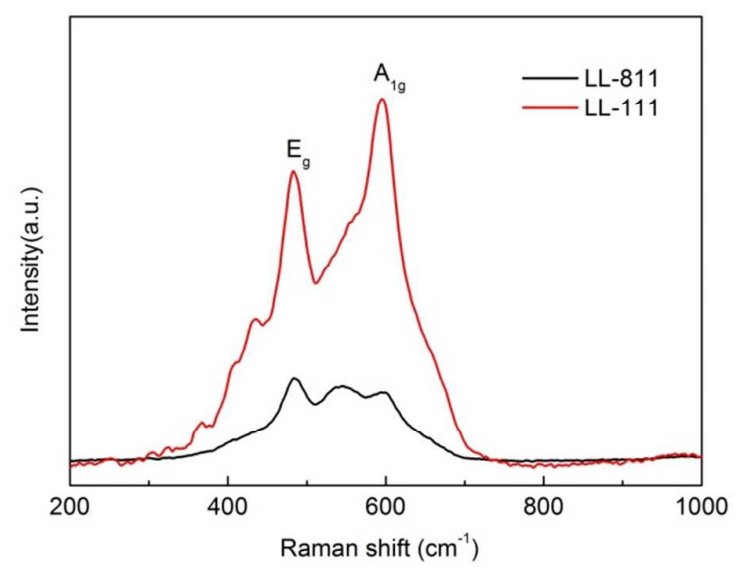

Figure S2 Raman results of pristine materials. 

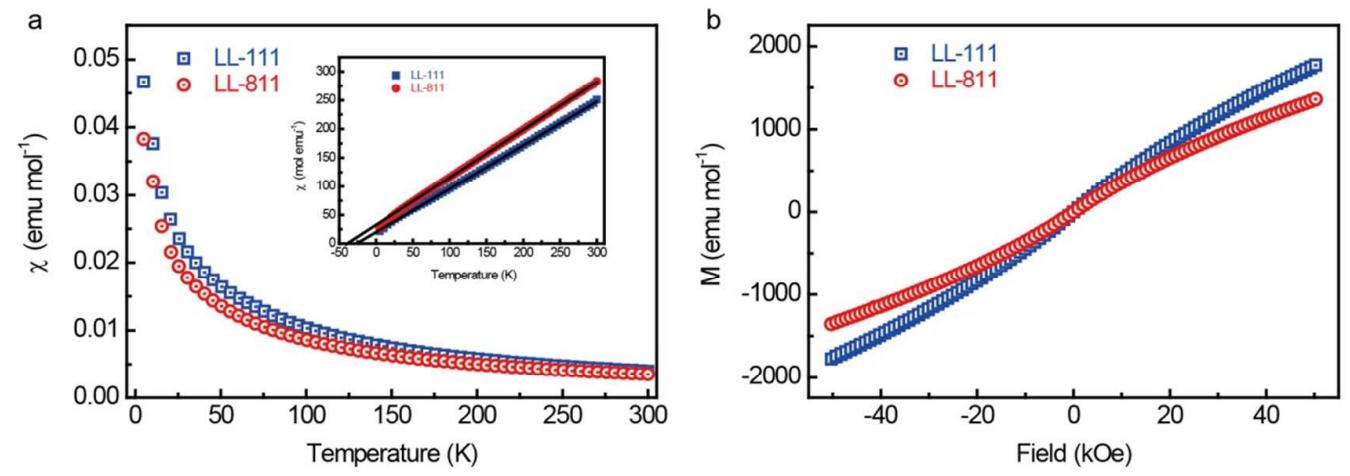

Figure S3. The magnetic measurement results. (a)Temperature dependence of the molar magnetic susceptibility of pristine material (b) magnetization curves measured at $5 \mathrm{~K}$. The pristine sample expresses the paramagnetic behavior obeying the Curie-Weiss law at temperature above $100 \mathrm{~K}$. The Weiss temperature of LL-811 and LL-111 was calculated to be $-41 \mathrm{~K}$ and $-30 \mathrm{~K}$, respectively. The more negative Weiss temperature of LL-811 indicates the presence of antiferromagnetic interaction in the material. The calculated theoretical magnetic moments was $2.77 \mu_{\mathrm{B}}(0.55 \mathrm{~mol}$ of $\mathrm{Mn}^{4+}\left(\mathrm{S}=3 / 2,3.87 \mu_{\mathrm{B}}\right), 0.05 \mathrm{~mol}$ of $\mathrm{Ni}^{2+}\left(\mathrm{S}=1,2.81 \mu_{\mathrm{B}}\right)$ and $0.35 \mathrm{~mol}$ of $\mathrm{Ni}^{3+}(\mathrm{S}=1 / 2$, $1.73 \mu_{\mathrm{B}}$ ), based on the molecular $0.5 \mathrm{Li}_{2} \mathrm{MnO}_{3} \cdot 0.5 \mathrm{LiNi}_{0.8} \mathrm{Co}_{0.1} \mathrm{Mn}_{0.1} \mathrm{O}_{2}$. The effective magnetic moment calculated from the plot of inverse magnetic susceptibility vs. temperature was $3.01 \mu_{\mathrm{B}}$. This can be explained by a combination of $0.55 \mathrm{~mol}$ of $\mathrm{Mn}^{4+}\left(\mathrm{S}=3 / 2,3.87 \mu_{\mathrm{B}}\right), 0.17 \mathrm{~mol}$ of $\mathrm{Ni}^{2+}\left(\mathrm{S}=1,2.81 \mu_{\mathrm{B}}\right)$ and $0.23 \mathrm{~mol}$ of $\mathrm{Ni}^{3+}(\mathrm{S}=1 / 2$, $\left.1.73 \mu_{\mathrm{B}}\right)$ and certified that some $\mathrm{Ni}^{2+}$ ions in the lithium layer. 

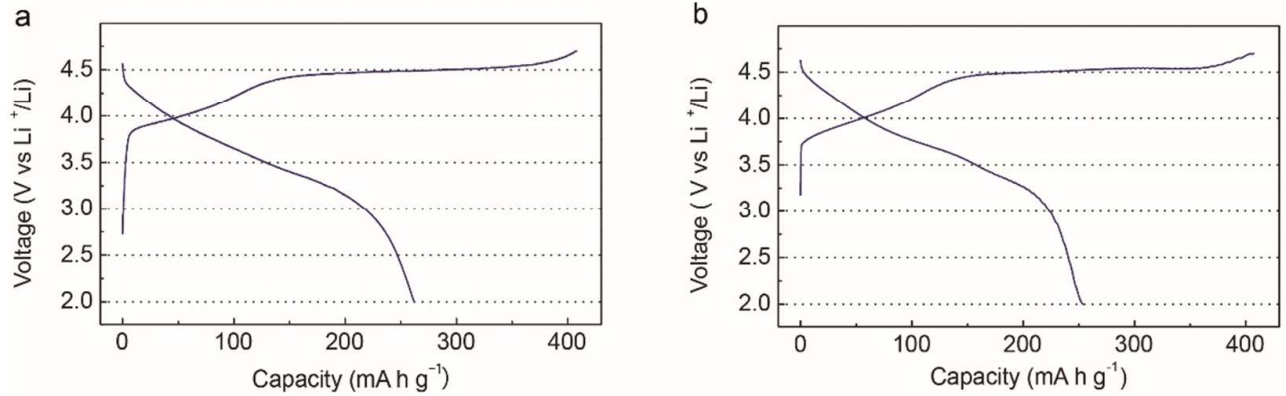

Figure S4. First charge-discharge profiles. (a) LL-111 electrodes at a current density of $0.05 \mathrm{C}\left(1 \mathrm{C}=250 \mathrm{~mA} \mathrm{~g}^{-1}\right) 260 \mathrm{mAh} \mathrm{g}^{-1}$ specific capacities can be obtained. (b) LL-811 electrodes at a current density of $0.05 \mathrm{C}\left(1 \mathrm{C}=250 \mathrm{~mA} \mathrm{~g}^{-1}\right) 253 \mathrm{mAh} \mathrm{g}^{-1}$ specific capacities can be obtained. Compare the two charge-discharge profiles can certified that the component of the high nickel content $\mathrm{Li}$-rich material of LL-811 is $0.5 \mathrm{Li}_{2} \mathrm{MnO}_{3} \cdot 0.5 \mathrm{LiNi}_{0.8} \mathrm{Co}_{0.1} \mathrm{Mn}_{0.1} \mathrm{O}_{2}$. 


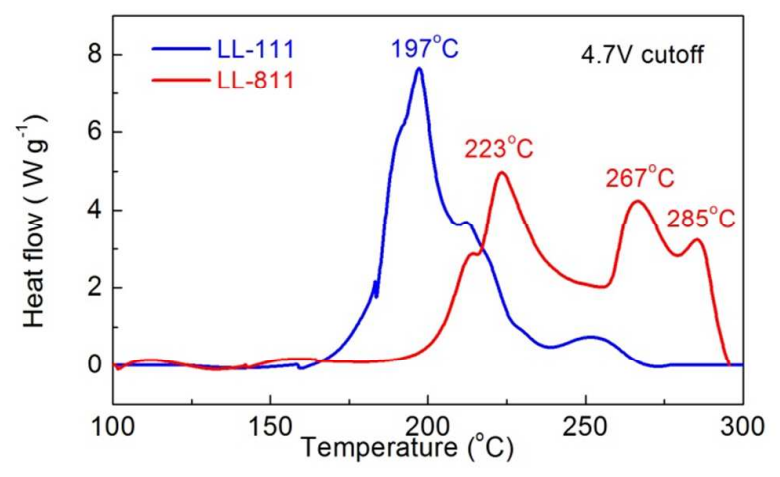

Figure S5. Differential scanning calorimetry profiles of the delithiated Li-rich cathode materials. The electrode materials were constant-voltage charge to $4.7 \mathrm{~V}$ before disassembling. 

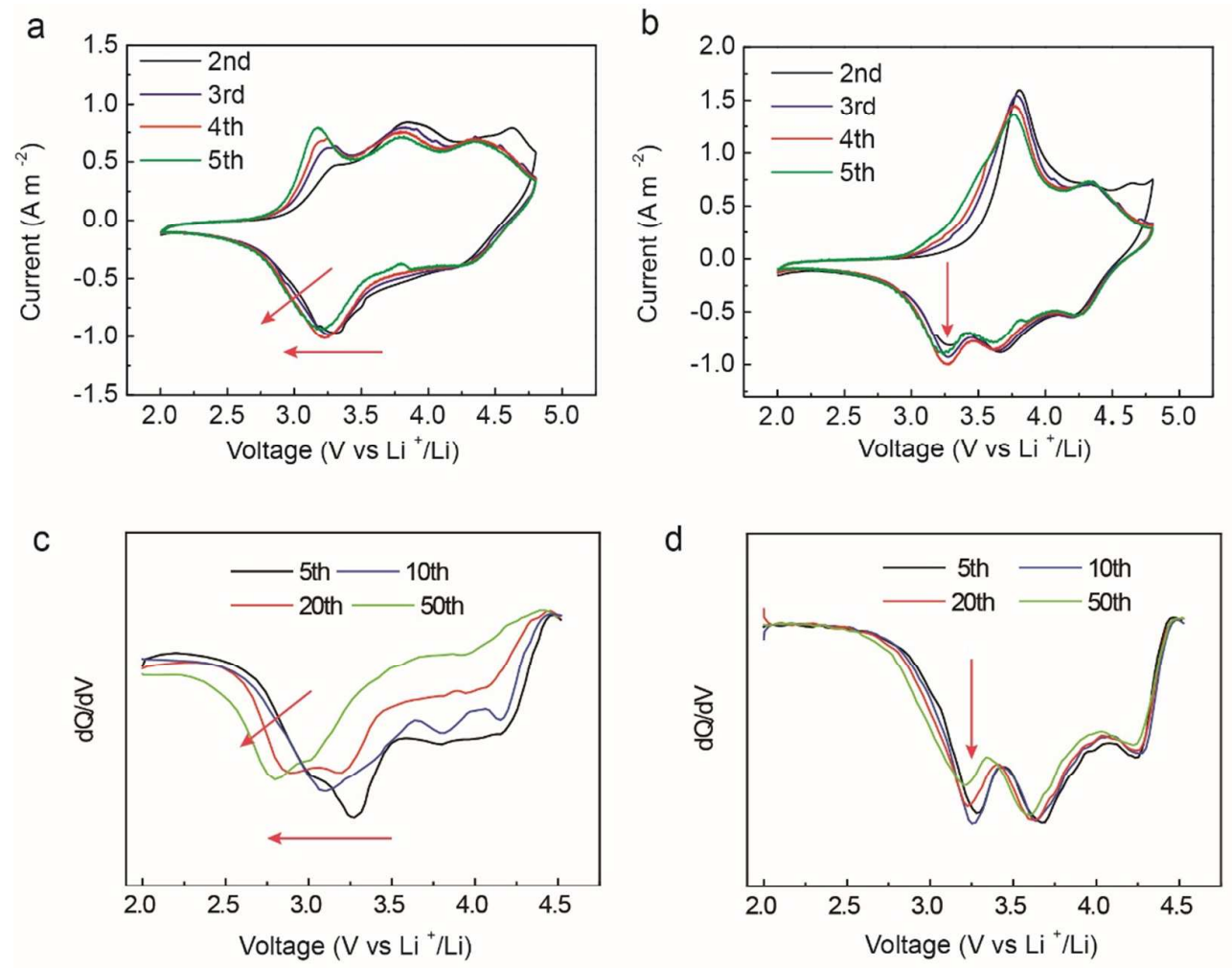

Figure S6 CV and dQ/dV plots of LL-111 and LL-811. (a) CV plot of LL-111 electrode at scan rate $0.05 \mathrm{mV} \mathrm{s}^{-1}$. (b) CV plot of LL-811 electrode at scan rate 0.05 $\mathrm{mV} \mathrm{s}^{-1}$. (c) dQ/dV plot of LL-111 electrode. (d) dQ/dV plot of LL-811 electrode. The $\mathrm{CV}$ and $\mathrm{dQ} / \mathrm{dV}$ results of both LL-111 and LL-811 electrodes clearly show that high nickel content Li-rich material of LL-811 $0.5 \mathrm{Li}_{2} \mathrm{MnO}_{3} \cdot 0.5 \mathrm{LiNi}_{0.8} \mathrm{Co}_{0.1} \mathrm{Mn}_{0.1} \mathrm{O}_{2}$ expresses the negligible voltage decay problem. 


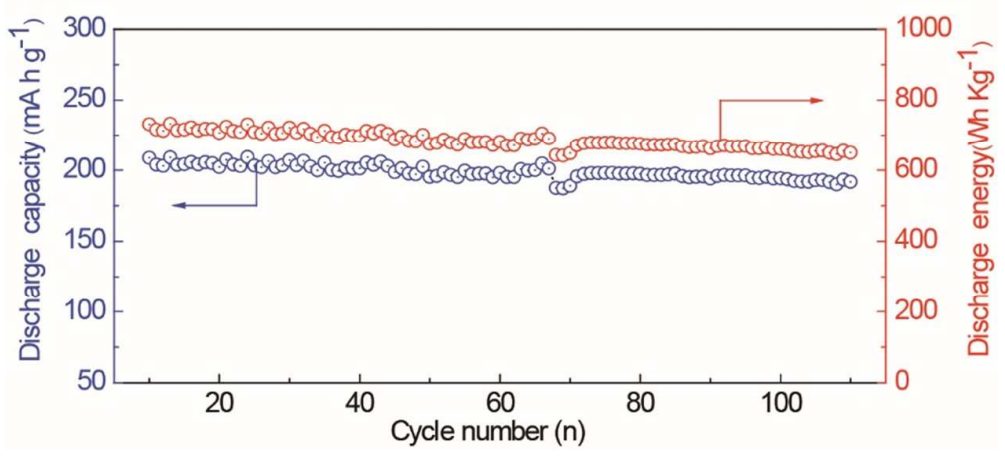

Figure S7. Specific capacity and specific energy as function of cycle number of LL-811 electrode. The specific energy $(E)=$ specific capacity $(C) \times$ average voltage (V), so the voltage fade after 100 cycles is $\mathrm{V}_{10}-\mathrm{V}_{110}=\mathrm{V}_{10} \times\left[1-\left(\mathrm{C}_{10} \times \mathrm{E}_{110}\right) /\left(\mathrm{C}_{110} \times\right.\right.$ $\left.\mathrm{E}_{10}\right)$ ] among which $\mathrm{E}_{110} / \mathrm{E}_{10}=89 \%, \mathrm{C}_{110} / \mathrm{C}_{10}=92 \%, \mathrm{~V}_{10}=3.6 \mathrm{~V}$. The voltage fade after 100 cycles calculated is $117 \mathrm{mV}$. 


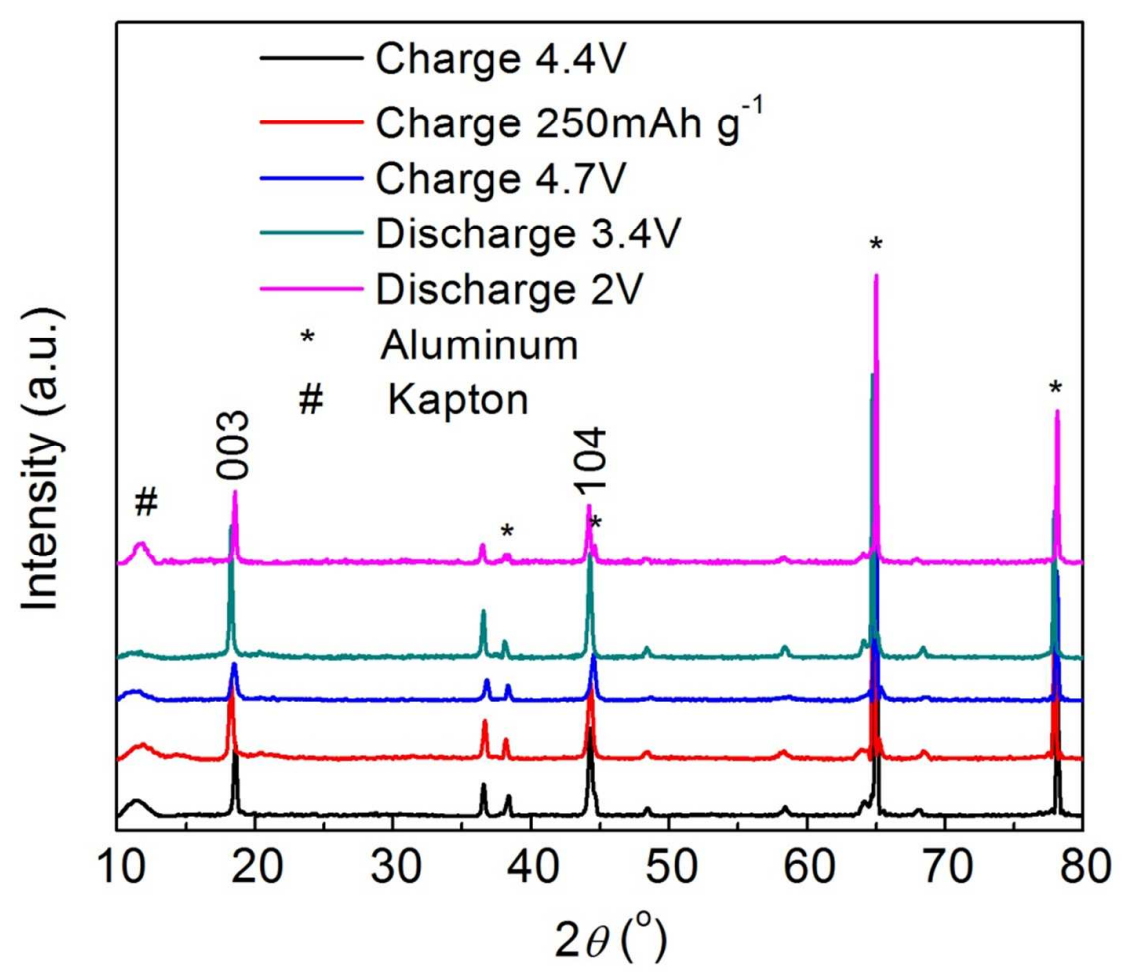

Figure S8 Ex situ XRD results of LL-811during the first charge discharge process. 


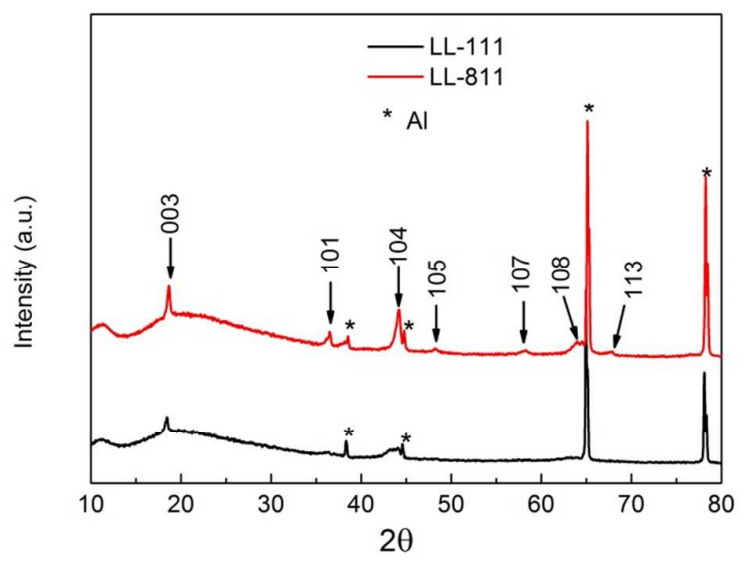

Figure S9. Ex situ XRD results of LL-111 and LL-811 electrodes after 50 cycles. After 50 cycles under the current density of $0.2 \mathrm{C}$, all the layered peaks can be clearly indexed for LL-811.while, in the LL-111 electrode only (003) and (104) peaks can be observed 
Table S1 Rietveld Refinement results of LL-111 pristine material in the $R \overline{3} m$ Space Group. Only the occupancies related to $\mathrm{Ni} / \mathrm{Li}$ exchange between the TM slab and the $\mathrm{Li}$ slab have been refined.

\begin{tabular}{|c|c|c|c|c|c|c|}
\hline \multirow[b]{3}{*}{ atom } & \multicolumn{2}{|c|}{ Sgr } & \multicolumn{2}{|c|}{$\mathbf{R} \overline{\mathbf{3}} \mathbf{m}$} & Bragg & \multirow[t]{2}{*}{ R-factor $=7.49$} \\
\hline & & & $=2.8$ & & $\mathrm{C}=14.18(2) \AA$ & \\
\hline & site & $x$ & y & z & Occ $\cdot$ theo & Occ $\cdot$ refined \\
\hline $\mathrm{Li}$ & $3 b$ & 0 & 0 & 0.5 & 1.0000 & $0.9823(17)$ \\
\hline $\mathrm{Ni}$ & $3 b$ & 0 & 0 & 0.5 & 0.0000 & $0.0177(17)$ \\
\hline $\mathrm{Ni}$ & $3 a$ & 0 & 0 & 0 & 0.1300 & $0.1113(17)$ \\
\hline $\mathrm{Li}$ & $3 a$ & 0 & 0 & 0 & 0.2000 & $0.2177(17)$ \\
\hline $\mathrm{Mn}$ & $3 a$ & 0 & 0 & 0 & 0.5400 & 0.5400 \\
\hline Co & $3 a$ & 0 & 0 & 0 & 0.1300 & 0.1300 \\
\hline 0 & $6 c$ & 0 & 0 & 0.26 & 1.000 & 1.0000 \\
\hline
\end{tabular}


Table S2 Rietveld Refinement results of LL-811 pristine material in the $R \overline{3} m$ Space Group. Only the occupancies related to $\mathrm{Ni} / \mathrm{Li}$ exchange between the TM slab and the $\mathrm{Li}$ slab have been refined.

\begin{tabular}{|c|c|c|c|c|c|c|}
\hline \multirow[b]{3}{*}{ atom } & \multirow{2}{*}{\multicolumn{2}{|c|}{ Sgr }} & \multirow{2}{*}{\multicolumn{2}{|c|}{$\begin{array}{l}\mathbf{R} \overline{3} \mathbf{m} \\
\mathrm{a}=2.86(2) \AA\end{array}$}} & \multicolumn{2}{|c|}{ Bragg R-factor $=4.975$} \\
\hline & & & & & $\mathrm{c}=14.19(2) \AA$ & \\
\hline & site & $x$ & $\mathrm{y}$ & z & Occ .theo & Occ - refined \\
\hline $\mathrm{Li}$ & $3 b$ & 0 & 0 & 0.5 & 1.0000 & $0.9230(14)$ \\
\hline $\mathrm{Ni}$ & $3 b$ & 0 & 0 & 0.5 & 0.0000 & $0.0770(14)$ \\
\hline $\mathrm{Ni}$ & $3 a$ & 0 & 0 & 0 & 0.3333 & $0.2563(14)$ \\
\hline $\mathrm{Li}$ & $3 a$ & 0 & 0 & 0 & 0.2000 & $0.2770(14)$ \\
\hline $\mathrm{Mn}$ & $3 a$ & 0 & 0 & 0 & 0.4583 & 0.4583 \\
\hline Co & $3 a$ & 0 & 0 & 0 & 0.0416 & 0.0416 \\
\hline 0 & $6 c$ & 0 & 0 & 0.26 & 1.0000 & 1.0000 \\
\hline
\end{tabular}


Table S3 Summarized the voltage decay of advanced Li-rich cathode materials.

\begin{tabular}{ccccc}
\hline Approach & Test conditions & $\begin{array}{c}\text { cycle number } \\
(\mathrm{n})\end{array}$ & $\begin{array}{c}\text { Voltage decay } \\
\mathrm{mV}\end{array}$ & reference \\
Hydrazine treated & $2-4.6 \mathrm{~V}, 1 \mathrm{C}, 24{ }^{\circ} \mathrm{C}$ & $5-125$ & 150 & 1 \\
$\mathrm{Mg}^{2+}$ doped & $2-4.7 \mathrm{~V}, 1 \mathrm{C}, 60^{\circ} \mathrm{C}$ & $1-250$ & 600 & 2 \\
GO coated & $2-4.7 \mathrm{~V}, 1 \mathrm{C}, 60^{\circ} \mathrm{C}$ & $1-100$ & 200 & 3 \\
Exposed \{010\} planes & $2-4.8 \mathrm{~V}, 0.1 \mathrm{C}, 30^{\circ} \mathrm{C}$ & $1-80$ & 300 & 4 \\
$\mathrm{~F}^{+}$doped & $2-4.8 \mathrm{~V}, 0.2 \mathrm{C}, 25^{\circ} \mathrm{C}$ & $1-100$ & 170 & 5 \\
This work & $2-4.7 \mathrm{~V}, 0.2 \mathrm{C}, 25^{\circ} \mathrm{C}$ & $1-200$ & 201 & $/$ \\
\hline
\end{tabular}

\section{Supporting References}

(1). Oh, P.; Myeong, S.; Cho, W.; Lee, M. J.; Ko, M.; Jeong, H. Y.; Cho, J., Superior Long-Term Energy Retention and Volumetric Energy Density for Li-Rich Cathode Materials, Nano Lett. 2014, 14, 5965-5972.

(2). Liu, W.; Oh, P.; Liu, X.; Myeong, S.; Cho, W.; Cho, J., Countering Voltage Decay and Capacity Fading of Lithium-Rich Cathode Material at $60{ }^{\circ} \mathrm{C}$ by Hybrid Surface Protection Layers, Adv. Energy Mater. 2015, 5, 1500274.

(3). Oh, P.; Ko, M.; Myeong, S.; Kim, Y.; Cho, J., A Novel Surface Treatment Method and New Insight into Discharge Voltage Deterioration for High-Performance $0.4 \mathrm{Li}_{2} \mathrm{MnO}_{3}-0.6 \mathrm{LiNi}_{1 / 3} \mathrm{Co}_{1 / 3} \mathrm{Mn}_{1 / 3} \mathrm{O}_{2}$ Cathode Materials, Adv. Energy Mater. 2014, 4, 1400631.

(4). Chen, L.; Su, Y.; Chen, S.; Li, N.; Bao, L.; Li, W.; Wang, Z.; Wang, M.; Wu, F., Hierarchical $\mathrm{Li}_{1.2} \mathrm{Ni}_{0.2} \mathrm{Mn}_{0.6} \mathrm{O}_{2}$ Nanoplates with Exposed $\{010\}$ Planes as High-Performance Cathode Material for Lithium-Ion Batteries, Adv. Mater. 2014, 26, 6756-6760.

(5). Li, L.; Song, B. H.; Chang, Y. L.; Xia, H.; Yang, J. R.; Lee, K. S.; Lu, L., Retarded Phase Transition by Fluorine Doping in Li-Rich Layered $\mathrm{Li}_{1.2} \mathrm{Mn}_{0.54} \mathrm{Ni}_{0.13} \mathrm{Co}_{0.13} \mathrm{O}_{2}$ Cathode Material, J. Power Sources 2015, 283, 162-170. 